\title{
HISTOLOGICAL CHANGES IN KIDNEY STRUCTURE FOLLOWING A LONG - TERM ADMINISTRATION OF PARACETAMOL (ACETAMINOPHEN) IN PREGNANT SPRAGUE DAWLEY RATS.
}

\author{
R. E. UCHEYA and J. C. IGWEH ${ }^{1}$ \\ Departments of Human Anatomy and Physiology ${ }^{l}$, College of Medicine, University of Nigeria, Enugu \\ Campus, Enugu, Nigeria.
}

\begin{abstract}
Summary: Histological changes in kidney structure following paracetamol administration in pregnant Sprague - Dawley rats were studied. 10 Sprague-Dawley rats divided into five animals per group were used for the study. They were divided into two groups (A and B). Group A served as a control group, while group B received $7.3 \mathrm{mgx} 3 / \mathrm{kg} /$ day of paracetamol from $10^{\text {th }}$ day of gestation till the $13^{\text {th }}$ day after parturition. The drug was administered by gavage. They were allowed free access to feed and water ad libitum. The maternal rats were then sacrificed for tissue processing. Three deaths were recorded amongst the maternal rats in the paracetamol treated group during parturition and a prolonged gestation period was also observed in the same animals while two maternal rats had a normal gestation period and a safe parturition. Histopathology results of the maternal control animals showed normal kidney architecture (very minimal capsular spaces and rounded glomeruli intimately surrounded by the Bowman's capsule). Two of the paracetamol treated maternal rats that had a safe parturition at the end of the normal gestation period and showed vascular congestion and glomeruli haemorrhage, while one of the maternal rats that had prolonged gestation period (44 days) with signs of abnormally high bleeding during parturition showed higher degree of kidney derangement which was evidenced by shrunken glomerulus's plus droplets in the tubules, vascular congestion, haemorrhage and tubular necrosis. These findings reflect derangement of kidney architecture. The results suggest that paracetamol though considered safe at a considerable low dose especially in pregnant state, could cause kidney derangement during pregnancy.
\end{abstract}

Keywords: Over-the-Counter-mixture: paracetamol, kidney toxicity, Pregnancy.

\begin{abstract}
Introduction
Paracetamol (Acetaminophen) was established in 1946, as the major constituent of phenacetin a white crystalline substance used to reduce body temperature and relieve pain. It first became available in the UK in 1956 and was included in the British pharmacopoeia in 1963. The precise mechanism of its action is not entirely clear, although it appears to work by inhibiting the production centrally (in the brain) of prostaglandins (substances that cause blood vessels to contract). It is particularly effective in treating common headache, when taken in combination with codeine or other drugs. It is used to control mild to moderate pain. It is the most widely use medicine for the purposes of relieving pain and fever, which is the most common clinical condition experienced by pregnant women, with some 4,100 million tablets containing paracetamol being taken annually in the UK for a wide range of common ailments. When taken at the
\end{abstract}

recommended dosage, there are virtually no adverse effects and there are almost no groups of people or conditions for which it is not appropriate. It causes less gastric precipitation than aspirin. The main concern with paracetamol is death resulting from hepatic toxicity (poisoning of the liver) and nephrontoxicity following overdose, either accidental or deliberate (Encarta Encyclopaedia 2002).

Many workers had in the past established the relationship between the use of non-steroidal anti-inflammatory drugs (NSAIDS) as tocolitics in pregnancy and the incidence of malformations in neonates of mothers given nimesulides (a NSAIDS) in the 3rd trimester of pregnancy. Peruzzi (1990) and Balasubramaniam (2000) reported a reduced renal cortical volume and size following selective inhibition of cyclooxygenase -2 to human neonates, similar reports were given by komhoff et al (2000) 
with respect to mice and rat. Lesko et al (1993), Peruzzi et al (1999), Balasubramaniam and Komhoff et al, (1997) reported glomerular hypoplasia in mice and rats antenatally exposed to these drugs. Peruzzi and his colleagues (1990) reported End-stage renal failure in neonates following the use of a cyclooxygenase-2 selective inhibitor (nimesulide) for the treatment of preterm labour about the 26th week of pregnancy. This report was confirmed by Balasubramaniam (2000) who also reported renal dysgenesis and malformations in mothers given the same drug (nimesulide) about the 30th week of pregnancy. Mesembe et al (2004) reported the incidence of nephrotoxicity and hepatic toxicity following the use of paracetamol and panadol extra without vitamine $\mathrm{E}$ supplementation.

Elseviers and De-Broe (1998) and Encarta Encyclopaedia (2002) found that the use of "over-the-counter analgesic mixtures" was a major causative factor of this problem. The causes of "over- the- counter" administration and abuse of drugs in Nigeria include the deteriorating economy, poor financial status of the people and illiteracy, which is the major predisposing factor to unawareness and ignorance of the effects of drug abuse. Due to financial constraints majority of Nigerians cannot afford to pay the necessary fees in a hospital hence they rather choose to go to the patent medicine shops to buy drugs, or get treatment. In some instances people in some remote rural areas where hospitals have not been sited, out of necessity patronize the patent medicine shops. Consequently, many Nigerians including pregnant women are exposed to the use of the "over-the-counter" analgesics including acetaminophen such as paracetamol. This is despite the fact that little has been reported as to the effects of neprotoxicity of this drug in pregnant women. It is therefore essential that a study of the most common of these drugs paracetamol be done in pregnant laboratory animals as a pointer to their effects on the pregnant women.

The above studies encompassed the effects of NSAIDS (nimesulide and paracetamol) in neonates following maternal exposure to this drug in pregnancy, and the effects in non-pregnant state, but the present study is aimed at investigating the effects of paracetamol on the kidney of maternal rats. This is based on the fact that: (1) they induced kidney toxicity when administered without vitamin E supplementation in Whister rats (Mesembe et al 2004), (2) the minimum amount of paracetamol for toxicity, to occur in majority of adults of average size (65 $100 \mathrm{~kg} / 143-220 \mathrm{Ib})$ are in excess of $10-15 \mathrm{~g}$ $(150 \mathrm{mg} / \mathrm{kg}$ or $68 \mathrm{mg} / \mathrm{Ib})$, equivalent to 20 to 30 tablets and that in rare circumstances, certain individuals die after taking less than the estimated minimum threshold toxic dose because of higher sensitivity to the toxic effects of paracetamol, hence individual risk of toxicity following paracetamol over dose can be difficult to assess (3) They were documented as tolerable (safe) during pregnancy, especially when taken below certain doses.

\section{Materials and Method Animals}

Ten adult female Sprague - Dawley rats were procured from the Animal house of University of Nigeria, Enugu Campus and kept in the animal house of physiology department, college of medicine Enugu campus for 2 weeks for acclimatization. They were housed in cages measuring 11 by $7 \mathrm{~cm}$ and were allowed free access to food and water $a d$ libitum. Individual identification of the animals were done by the number of stokes marked on their tails.

\section{Experimental Design}

Ten adult female Sprague-Dawley rats weighing between $165 \mathrm{~g}-179 \mathrm{~g}$ were randomly divided into two groups (A, \& B) of five rats each. Animals' in-group A received distilled water orally and served as control while paracetamol treated rats (group B) received doses of $7.3 \mathrm{mg} / \mathrm{kg} /$ day respectively by gavage. The animals were allowed feed and water liberally. The treatment commenced from $10^{\text {th }}$ day of gestation to $13^{\text {th }}$ day after parturition. This is with a view to highlighting the effects of long usage of paracetamol. The maternal rats were then sacrificed by cervical dislocation for tissue processing.

\section{Experimental Procedure}

The reproductive status and estrous period of the animals were determined by obtaining their virginal smears. After two complete regular cycles, timed mating of female animals was done on the night of the pro-estrous (N) phase of the cycle. In the morning following mating, vaginal smears were taken again. The presence of spermatozoa and squamus cells in the smear confirmed mating and fertilization of ovulated spermatozoa. The sperm - positive morning was thus designated day 0 of pregnancy. The maternal rats in the experimental and control groups were exposed to chloroform and opened up, in other to obtain their kidneys, they were immediately fixed in $10 \%$ Formalin for about $24 \mathrm{hrs}$. 
Photomicrographs of tissues were then examined for histological changes.

\section{Results}

Histological findings

Histopathological examination of the control animals (group A) showed normal kidney architecture and no morbidity was recorded in this group (Fig. 1). In the paracetamol treated animals (Group B) two of the maternal rats had a normal gestational period and parturition, while three of the maternal rats had a prolonged gestational period of (37 - 44 days), at the end they presented signs of bleeding and died a day after. Two of the paracetamol treated maternal rats that had a safe parturition at the end of the normal gestational period showed marked reduction in size of the glomerulus (hypoplasia) and apparently wide capsular spaces some of which lacked glomeruli (Fig.lla $\&$ llb). The maternal rat that had prolonged gestational period and on the 44th day presented with signs of bleeding during parturition, showed shrunken glomeruli plus droplets in the tubules, vascular congestion, haemorrhage and tubular necrosis (Fig. 1ll).

Effects Of Paracetamol On Maternal Weight 13 Days After Parturition.

Our statistical analysis revealed that paracetamol treated maternal animals had a significant weight loses $(\mathrm{P}<0.05)$. This is also highly indicative by a greater weight loss of $7.41 \%$ when compared to the control animals.

Table 1: Showing Effects of Paracetamol on the maternal body weight (All weights in grams)

\begin{tabular}{|c|c|c|c|c|c|c|}
\hline $\begin{array}{c}\text { Animal } \\
\text { Group }\end{array}$ & $\begin{array}{c}\text { Drugs } \\
\text { Administered }\end{array}$ & $\begin{array}{c}\text { Mean } \\
\text { Weight } \\
\text { before } \\
\text { Pregnancy } \\
\text { (a) }\end{array}$ & $\begin{array}{c}\text { Mean } \\
\text { Weight at } \\
10^{\text {th }} \text { Day } \\
\text { of } \\
\text { Pregnancy }\end{array}$ & $\begin{array}{c}\text { Mean } \\
\text { Weight at } \\
\text { 13th } \\
\text { Day after } \\
\text { Parturition } \\
\text { (b) }\end{array}$ & $\begin{array}{c}\text { Mean } \\
\text { weight } \\
\text { Difference } \\
(\mathrm{a}-\mathrm{b})\end{array}$ & $\begin{array}{c}\% \\
\text { Weight } \\
\text { Loss }\end{array}$ \\
\hline A & Control & $188.76 \pm 5.4$ & $395 \pm 3.1$ & $185.1 \pm 2.2$ & $25.66 \pm 3.1$ & $2.19 \%$ \\
\hline B & Paracetamol & $200.64 \pm 2.1$ & $213.2 \pm 4.2$ & $183.4 \pm 2.3$ & $* 39.24 \pm 1.2$ & $* 9.60 \%$ \\
\hline
\end{tabular}

*Significantly different from the value of control $P<0.05 ;$ All wt in $(g)$ Mean \pm SEM.

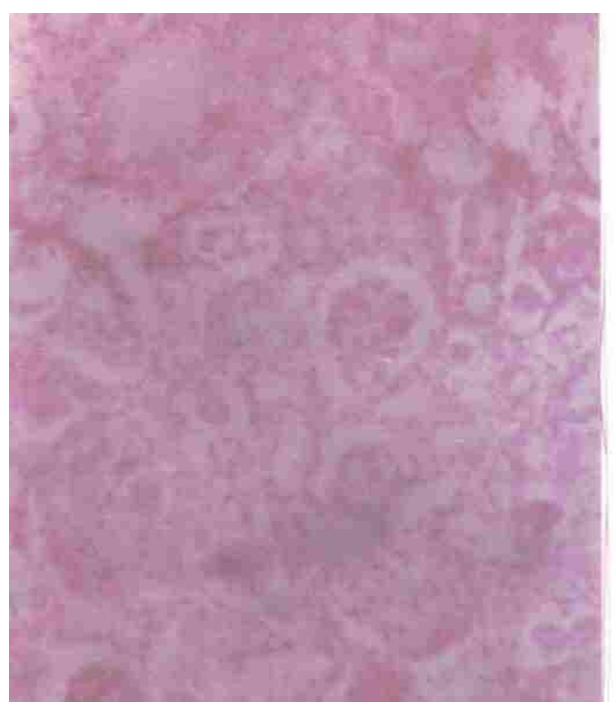

FIG 1: Cross - section of the kidney of pregnant control animals (group A). Stains: haematoxylin \& eosin. Magnification: X100.

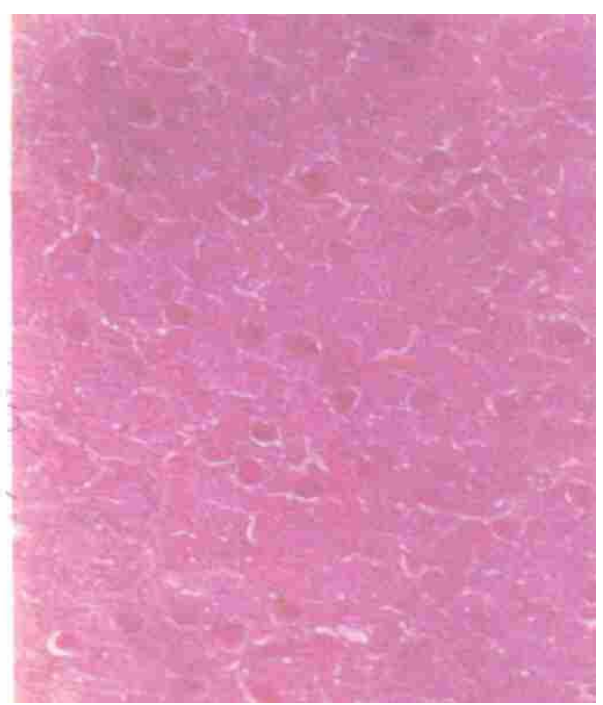

FIG. IIa: Cross - section of the kidney of pregnant Sprague - Dawley rats treated with Paracetamol for 24 days $\left(10^{\text {th }}\right.$ day of gestation $-13^{\text {th }}$ day after parturition) and sacrificed on the $24^{\text {th }}$ day. Stains: haematoxylin \&eosin. Magnification: X100 


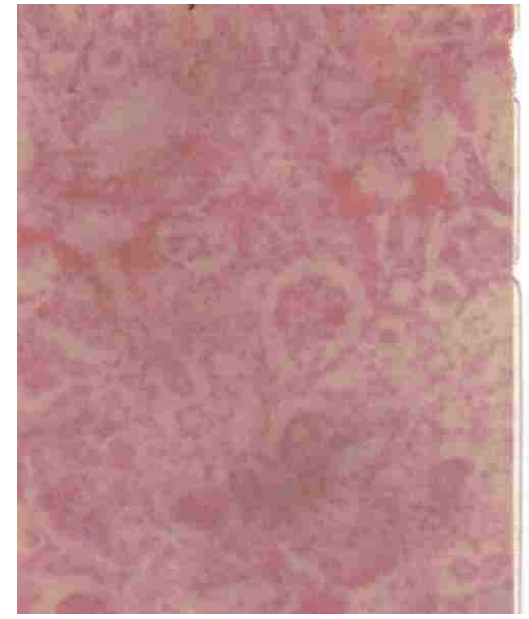

FIG. II b: Cross- section of the kidney of pregnant Sprague - Dawley rats treated with Paracetamol for 24 days $\left(10^{\text {th }}\right.$ day of gestation $13^{\text {th }}$ day after parturition) and sacrificed on the $24^{\text {th }}$ day. Stains: haematoxylin \& eosin. Magnification: X100.

\section{Discussion}

Paracetamol is a common household analgesic. Pregnant women commonly use it during pregnancy. However, its' indiscriminate use has been attributed to "over-the-counter" mixtures of analgesics. From our present investigation, we speculate that reduction in weight two weeks after parturition might have been due to a reduction in glomeruli size as shown on table one and in photomicrographs of Paracetamol treated animals. This is in conformity with stated law in a text by (Junqueira et al 1975). He documented that there is a relation between total glomerular volume and kidney weight expressed in a straight line on a logarithmic scale. Secondly it could be due to a compromised nutritional status of the maternal rats consequent on gastrointestinal tract derangement.

The death of three maternal rats shortly after bleeding during parturition could have been due to their prolonged hypersensitivity to Paracetamol which agrees with the statement cited by Microsoft Encyclopedia, (2002), that in lighter individuals toxic levels may be reached with fewer tablets, that is, 15tablets $(7.5 \mathrm{~g})$ in a person weighing $50 \mathrm{~kg}(110 \mathrm{lb})$, secondly that individual risk of toxicity following Paracetamol overdose can be difficult to assess, hence increased sensitivity to the toxic effects of Paracetamol may help to explain why, in rare circumstances, certain individuals die after taking less than the estimated minimum threshold toxic dose. Thirdly, that the main concern with

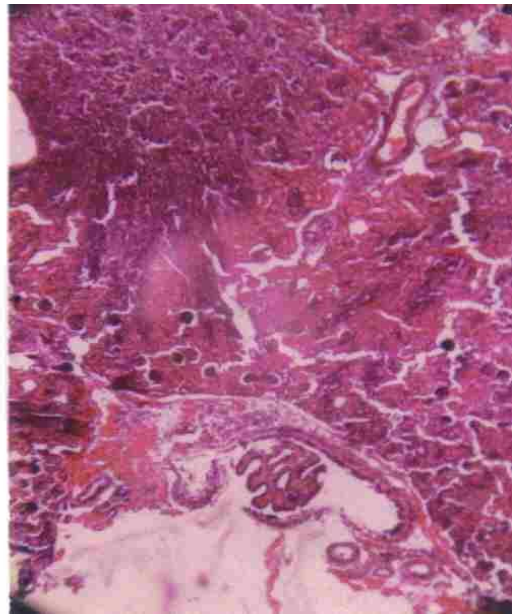

FIG.III: Cross - section of the kidney of pregnant Sprague - dawley rats treated with Paracetamol for 24 days $\left(10^{\text {th }}\right.$ day of gestation $-13^{\text {th }}$ day after parturition) and sacrificed on the $24^{\text {th }}$ day. Stains: haematoxylin \& eosin. Magnification: X40

Paracetamol is death resulting from hepatic toxicity and nephrotoxicity following overdose, either accidental or deliberate which is probably the reason for renal impairment shown in (Fig. 11-111).

We suggest that since the degree of individual sensitivity to Paracetamol toxicity presently cannot be assess, women should be wary of its indiscriminate use in pregnancy. Gynaecologist should endeavour to ensure that a comprehensive health talk is delivered during anti-natal clinics both in urban and rural communities on the effects of Paracetamol abuse in pregnancy. We conclude that a longterm use of Paracetamol in pregnant state might cause histological changes in the maternal kidney, which could probably lead to renal insufficiency or impairment after parturition, as evidenced in the photomicrographs of the kidney sections (Fig. 11-111). In conclusion, renal impairment or insufficiency seen in women after parturition could be the aftermath of indiscriminate use of Paracetamol in pregnancy.

\section{References}

Balasubramaniam, J. (2000). Nimesulide and neonatal renal failure. The Lancet 335:575.

Dollery, C., Boobis A. R. (1993). Paracetamol. In: Dollery C and Boobis A. R; Editors, Therapeutic Drugs. Churchill Livingstone. Vol. 2: 13.

Elseviers, M. M., De - Broe, M. E. (1998): Analgesic abuse in the elderly. Renal 
sequelae and management. Drugs. Aging. 12:391-400.

Elseviers, M. M., De-Broe, M. E. (1999): Analgesic nephropathy: is caused by multi - analgesic abuse or single substance use? DrugSafety. 20: 15-24.

Junqueira I. C., Carneiro J., Contropoulos A. (1975). In Basic Histology: Lange Medical Publications. Pp 355 - 365.

Komhoff, M., Grone, J., Klein, T., Seyberth, H. H., Nursing, R. M. (1997). Localization of zcox-1 and -2 in adult and foetal human kidneys: implication for renal function. Am. Physiol. 272:F460-8.

Lesko, S. M., Mitchel, A. A. (1995). An assessment of the safety of pediatric ibuprofen. A practitioner-based randomized clinical trial. JAMA 273:9293.
Mesembe, O. E., Igiri, A. O., Naikot, I., Ekam, V. S., Odukana, J. F., and Fischer, V. A. (2004). Liver and Kidney Morphologies Following Vitamin E Supplementation During Caffeinated and Non - Caffeinated Paracetamol Administration in Rats. $J$. Exp. \& Clin. Anat. 3 (1) 35 - 38.

Microsoft Encarta Encyclopedia, Standard (2002). Paracetmol in article outline. Pp 12.

Peruzzi, L., Gianogiio, B., Porcellini, M. G., Copper, R. (1999). Neonatal end - stage renal failure associated with maternal ingestion of cyclooxygenase - type - 1 selective inhibitor, nimesulide as tocolytic. The Lancet. 354:1615.

Received: $1 / 11 / 06$

Accepted: 22/12/06 